\title{
Role of Bisphosphonates as Adjuvants of Surgery in Giant Cell Tumor of Spine
}

\author{
CHAITANYA DEV PANNU, MS, DNB, MRCS, PANKAJ KANDHWAL, MS, VIJAY RAGHAVAN, MS, \\ SHAH ALAM KHAN, MBBS, MS, DNB, MRCSED, FRCS, MCHORTH, SHISHIR RASTOGI, MS, DNB, \\ ARVIND JAYASWAL, MS \\ Department of Orthopaedics, All India Institute of Medical Sciences, New Delhi, India
}

\begin{abstract}
Background: The role of bisphosphonates is well established in giant cell tumor of bone (GCTB) of extremities, but its role in spine GCTB is still not established. Our main purpose was to evaluate the role of bisphosphonates in spinal GCTB with the help of radiologic assessment.

Methods: A retrospective analysis of all spine GCTB patients who underwent an operation from July 2005 to January 2014 was done. Patients of spine GCTB in whom bisphosphonates were given constituted the study group. This group was compared to patients in whom bisphosphonates were not given. Preoperative and postoperative radiographs and CT scans were studied. A thorough evaluation of the presence of sclerosis was done on them. Bisphosphonates were considered to be effective if either sclerosis or new bone formation was present.

Results: A total of 13 cases of spine GCT underwent operation from July 2005 to January 2014. All patients of GCTB spine who underwent an operation after 2008 at our institute were given bisphosphonates postoperatively. Of 13 cases, bisphosphonates were given postoperatively in 6 patients: 5 patients were female and 1 patient was male. Of these 6 patients, 3 patients had sacrum GCTB and 1 patient each had T9, T11, and L5 vertebrae GCTB. Average follow-up period was 39.33 months (minimum follow-up was 18 months and maximum follow-up was 72 months). Postoperative sclerosis was present in all 6 patients. No recurrence of the tumor was present in the bisphosphonate group, but 2 patients had a recurrence in the group that did not receive bisphosphonates.

Conclusions: Bisphosphonates are effective and safe adjuvant therapy along with appropriate surgical intervention in spinal GCTBs and may have a role in decreasing the recurrence of this tumor.
\end{abstract}

Other \& Special Categories

Keywords: bisphosphonates, cryotherapy, radiotherapy, metastasis, osteoclast

\section{INTRODUCTION}

Giant cell tumor of bone (GCTB) is more common in the oriental and Eastern Asian population than the white one. It may account for $5 \%$ of bone tumors and more than $20 \%$ of benign bone tumors. ${ }^{1,2}$ It is quite common in the appendicular skeleton and most commonly found around the knee joint. ${ }^{3}$ The sacrum is the third most common site as far as incidence is concerned and incidence in the rest of the mobile spine accounts for only $2 \%$ to $4 \%$ of cases. ${ }^{4}$ The most commonly affected age group is usually 20 to 40 years, and there is slight female predilection. ${ }^{5}$

Although by now an ample amount of literature has been published regarding spine GCTBs, many questions about it are still unanswered. Spine GCTBs present with many challenges in management because they are quite adjacent to the neural tissue and present very late. They are commonly diagnosed when they become grade III after the destruction or expansion of the cortices. Complete resection is quite challenging because of difficulty of access, proximity to neural structures, and steep learning curves for the surgeons. ${ }^{6,7}$ Because of these limitations, oftentimes surgeons prefer marginal or intralesional excision, and what is considered the optimum treatment (ie, radical excision) is sidelined.

Many treatment modalities have been described for spine GCTB, like cement injection, phenol ablation, cryotherapy, radiotherapy, and surgical treatment, such as curettage or en bloc resection of the lesion and reconstruction. ${ }^{7}$ When surgery is not possible or would be associated with unacceptable toxicity, treatment with systemic therapies, such as bisphosphonate, denosumab, or radiation therapy, may be useful. Hence, needs-based and resultoriented preoperative planning has to be implemented. A treating physician should aim for tumor 
removal, prevention of recurrence, and preservation of spinal alignment and stability while maintaining the preoperative functioning of the spinal nerves. All these goals of surgery are considered difficult to achieve without violating one or the other, even in the hands of an experienced surgeon.

Recently, many studies have been published stating the role of bisphosphonates in GCTB in extremities. The benefit of systemic treatment with bisphosphonates in both resectable and nonresectable GCTB is quite encouraging. ${ }^{8,9}$ A meta-analysis carried out by Balke et $\mathrm{al}^{9}$ illustrated that overall recurrence rates of GCTB of appendicular skeleton in patients with resectable disease treated with adjuvant systemic bisphosphonates was $6.7 \%$ compared with $48.4 \%$ in patients not treated with adjuvant systemic bisphosphonates. However, its role in spinal GCTB has not yet been extensively studied. We present our experience of 13 patients with GCTB of the spine. These patients were managed by surgical and surgical plus postoperative bisphosphonates.

\section{MATERIALS AND METHODS}

All patients with giant cell tumor of the spine who underwent surgical excision/resection between July 2005 and January 2014 at the All India Institute of Medical Sciences, New Delhi, were included in the study. All patients underwent exhaustive preoperative workup, such as radiographs, computed tomography (CT) and magnetic resonance imaging (MRI), and biopsy, before surgical excision. Preoperative arterial embolization 24 to 48 hours prior to surgery was routine in all patients. Medical records were analyzed for the demographic attributes of the patients, site of the tumor, clinical symptoms, and symptom duration. Patients were treated depending on the amount of the osseous and extraosseous involvement, and the amount of the tissue required for the complete resection of the tumor tissuereconstructing the defect created while preserving the integrity of all the adjacent tissue. Operative and postoperative details were analyzed for the administration of the oral bisphosphonates. All patients who underwent operation after 2008 were administered $10 \mathrm{mg}$ of oral alendronate daily in the postoperative period for a period of 2 years; these patients formed the study group. Patients who underwent operation before 2008 did not receive bisphosphonates; they formed the control group. Patients were followed up at regular intervals for improvement in visual analog scale (VAS), Oswestry Disability Index (ODI), and neurologic status. Xrays were taken at 3-month intervals for first 6 months and then at 6-month intervals afterward. A CT scan was done after 2 years of surgery. All the radiographs and CT were evaluated by an expert radiologist for increased mineralization, increased cortical thickness of the remaining bone, new bone formation, and increased trabecular density in postoperative radiographs as well as CT scan. All of the above-mentioned radiologic attributes were considered to be the antiresorptive effect of bisphosphonate therapy and were termed as sclerosis. Recurrence of the tumor was evaluated by radiologic screening using X-rays and MRI. On X-rays recurrence will appear as progressive lysis of the parent bone or the bone graft, and on MRI local postoperative high signal within the surgical bed that exhibits a rounded masslike appearance with eccentric growth is highly suggestive of tumor.

Average follow-up period was 39.33 months (minimum follow-up was 18 months and maximum follow-up was 72 months).

\section{RESULTS}

A total of 13 cases of spine GCTB were operated on from July 2005 to January 2014 at our institute. In our study 8 patients were female and 5 patients were male, with ages ranging from 13 to 60 years and an average age of 33 years. A total of 6 patients had sacral involvement, 5 patients had lumbar involvement, and 2 patients had thoracic spine lesion. In lumbar spine 1 case was of L2 GCTB, 2 cases were of L4 GCTB, and 2 cases were of the L5 lesion. The thoracic spine was affected in 2 patients with the lesion in T9 and T11 vertebra. Most of the patients in our series were of late grade II or grade III histopathologically, and most them had taken some part of their treatment outside our center. Chief complaints were back pain with duration ranging from 3 to 48 months, whereas 4 patients presented with neurologic deficit. One patient was Asia A and 3 patients were Asia C. Neurology recovered in only 2 patients with Asia C. In 1 patient with Asia C it became Asia E, and in another it progressed to Asia D.

\section{Complications}

One patient underwent 7 operative procedures after the initial main surgery and died after 23 
Table 1. Patients who received bisphosphonates in the postoperative period.

\begin{tabular}{|c|c|c|c|c|c|c|c|}
\hline Name & Age, y/Sex & Site & Follow-up Period, mo & Sclerosis $+/-$ & Neurology Preoperative & Neurology Postoperative & Recurrence \\
\hline RM & $20 / \mathrm{M}$ & GCT sacrum & 72 & Present & Asia A & Asia A & Absent \\
\hline $\mathrm{Sh}$ & $13 / \mathrm{F}$ & GCT D9 & 30 & Present & Asia C & Asia D & Absent \\
\hline $\mathrm{M}$ & $22 / \mathrm{F}$ & GCT D11 & 55 & Present & Asia C & Asia E & Absent \\
\hline $\mathrm{Ma}$ & $24 / F$ & GCT L5 & 25 & Present but minimal & Asia E & Asia E & Absent \\
\hline $\mathrm{G}$ & $30 / \mathrm{F}$ & GCT sacrum & 24 & Present & Asia E & Asia E & Absent \\
\hline $\mathrm{Sa}$ & $33 / \mathrm{F}$ & GCT sacrum & 18 & Present & Asia E & Asia E & Absent \\
\hline
\end{tabular}

Abbreviation: GCT, giant cell tumor.

months. A total of 3 patients required subsequent debridement, including the one who died.

\section{Group 1}

Of 13 cases, bisphosphonates (Table 1) were given in 6 patients who underwent operation after 2008; 5 patients were female and 1 patient was male, with ages ranging from 13 to 33 years and an average age of 23.66 years. Of these 6 patients, 3 patients were of sacrum and 1 patient each was of D9, D11, and L5 vertebrae. Mean preoperative VAS score was 6 and postoperative VAS score was 2. Mean preoperative ODI score was 65 and postoperative ODI score at 1year follow-up was 8 . Average follow-up period was

\section{Y/F \\ Backache 6 months GCT D11 Vertebrae}

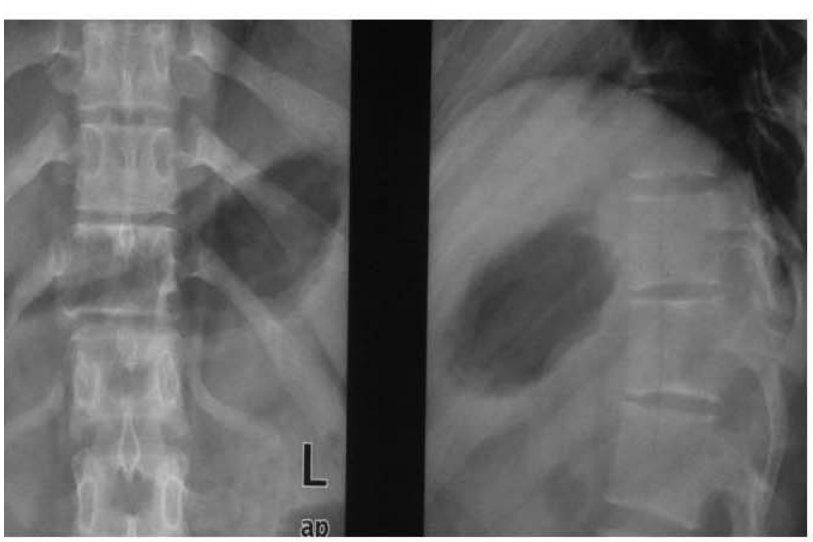

Pre Op X ray
39.33 months. Postoperative sclerosis was present in all 6 patients, as demonstrated in Figures 1 and 2. In a patient with L5 GCT minimal sclerosis (ie, minimal increased mineralization, cortical thickening, and increase in trabecular density), was visible in postoperative scans (Figure 3). There was no recurrence of tumor in this group.

\section{Group 2}

A total of 7 patients (Table 2) underwent operation before 2008, and postoperative alendronate was not administrated to them. Of these 7 patients, 3 were female and 4 were male, with an age range of 16 to 55 years and an average age of 34.57

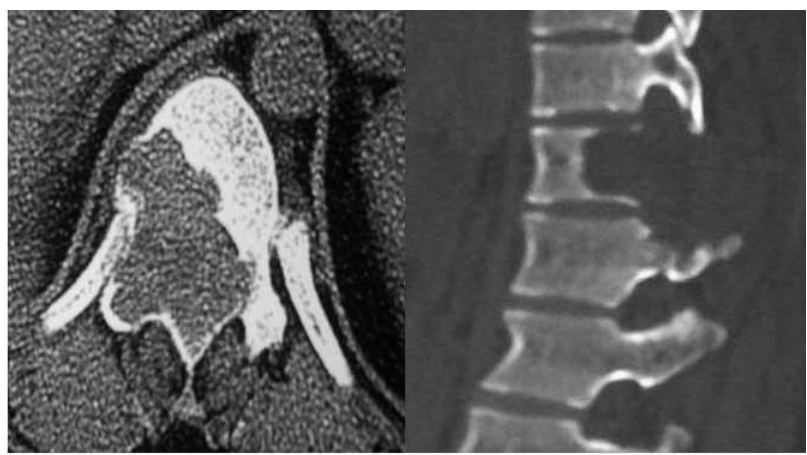

Pre OP CT

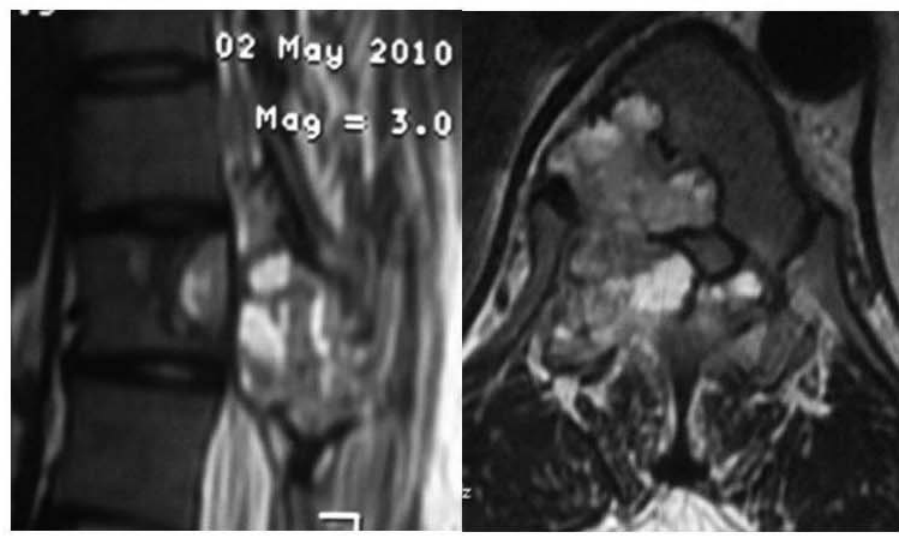

Pre op MRI T2 Image

Figure 1. Preoperative (pre-op) radiographs, computed tomography, (CT), and magnetic resonance imaging (MRI), of giant cell tumor of bone of D11 vertebrae. 


\section{Partial}

Vertebrectomy with Posterior instrumention with expendable cage

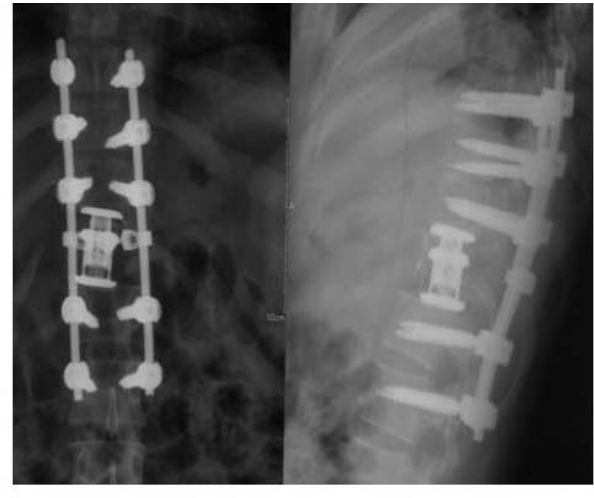

Immediate Post Op X Ray

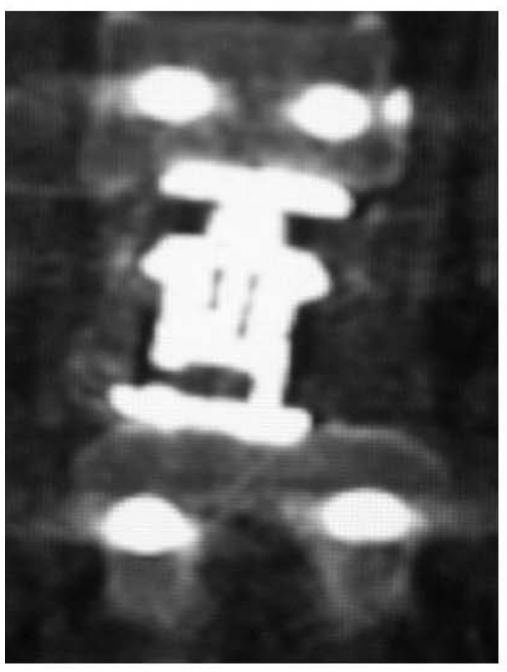

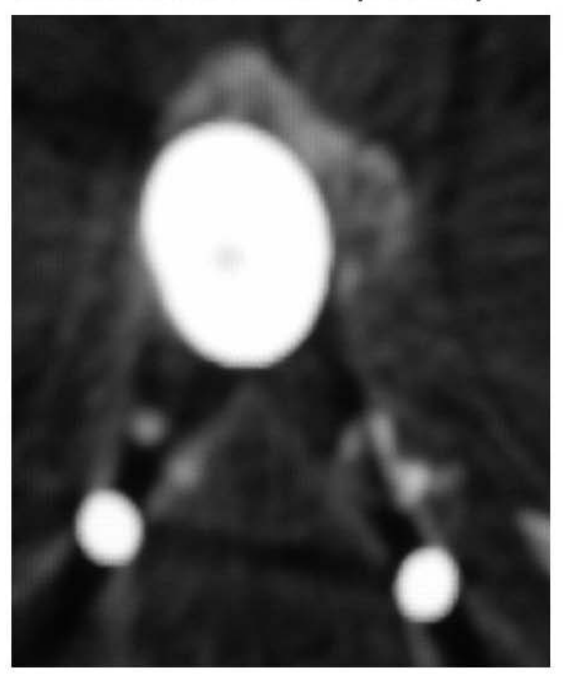

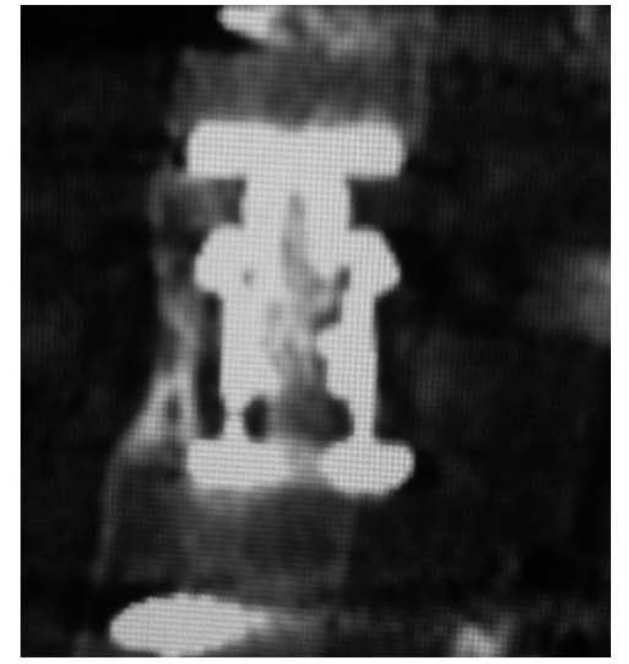

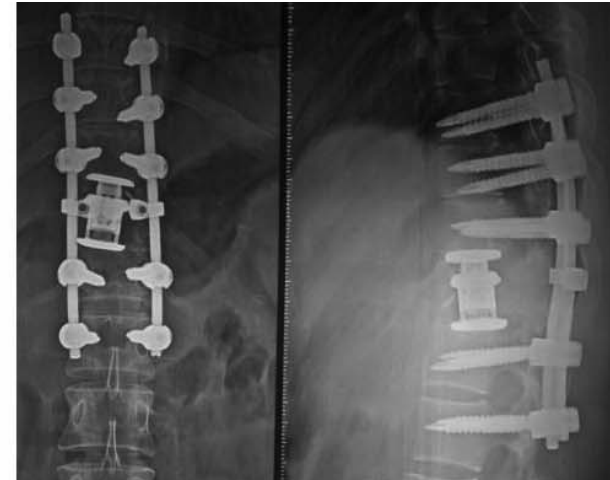

$\mathrm{X}$ ray after 6 months

\section{CT Scan at 2 Years interval}

Figure 2. Postoperative (pre-op) radiographs and computed tomography (CT) scan at an interval of 2 years showing sclerosis.

years. A total of 3 patients were of GCTB sacrum, 2 patients were of GCTB L5 vertebra, and 1 patient each was of GCTB L2 and L4 vertebra. Mean preoperative VAS score was 7 and postoperative VAS score was 4. Preoperative ODI score was 63 and postoperative ODI score was 15. Average follow-up period was 36.43 months. There was no sclerosis in this group, and recurrence of tumor occurred in 2 patients.

Comparison between 2 groups can be summarized in Table 3.

\section{DISCUSSION}

Giant cell tumor of bone was first reported by Cooper and Travers ${ }^{10}$ in 1818 , and it was formally defined by Jaffe et $\mathrm{al}^{11,12}$ in 1940. Giant cell tumors constitute about $5 \%$ of primary bone tumors and around $20 \%$ of all benign bone neoplasms. ${ }^{13}$ The most common site of occurrence is epiphysis of long bones. Occurrence in the spine is rare because only $2 \%$ to $5 \%$ of tumors are found in the vertebrae above the sacrum. ${ }^{14-16}$ The most commonly affected site in the spine is sacrum, followed by the thoracic, cervical, and lumbar vertebral segments in respective decreasing order of frequency. ${ }^{17}$ In our series 6 patients had sacral involvement, 5 patients had lumbar involvement, and 2 patients had thoracic spine lesion. A total of 11 of 13 patients in our study were ages 10 to 40 years, 8 patients were female, and 5 were male. Female preponderance and affection in the second to fourth decades of life is usually found in the spinal GCT. ${ }^{5}$

Although classified as benign, GCTB shows locally aggressive behavior. ${ }^{18-21}$ The treatment is mainly surgical and consists of intralesional curettage of the tumor followed by bone cement packing or bone grafting of the defect. Depending on the surgical procedure the local recurrence rate significantly varies from approximately $10 \%$ to $40 \%$. It is 
Partial Corpectomy with Pediculectomy with Cage fixation and Posterior Instrumentation was done
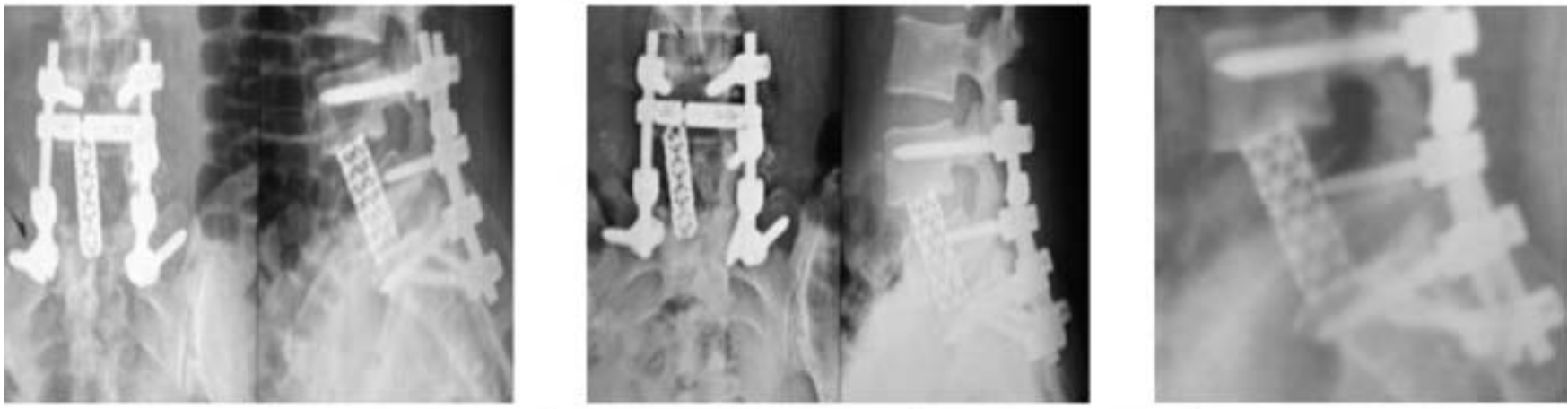

Radiographs at 6 months interval Post operatively
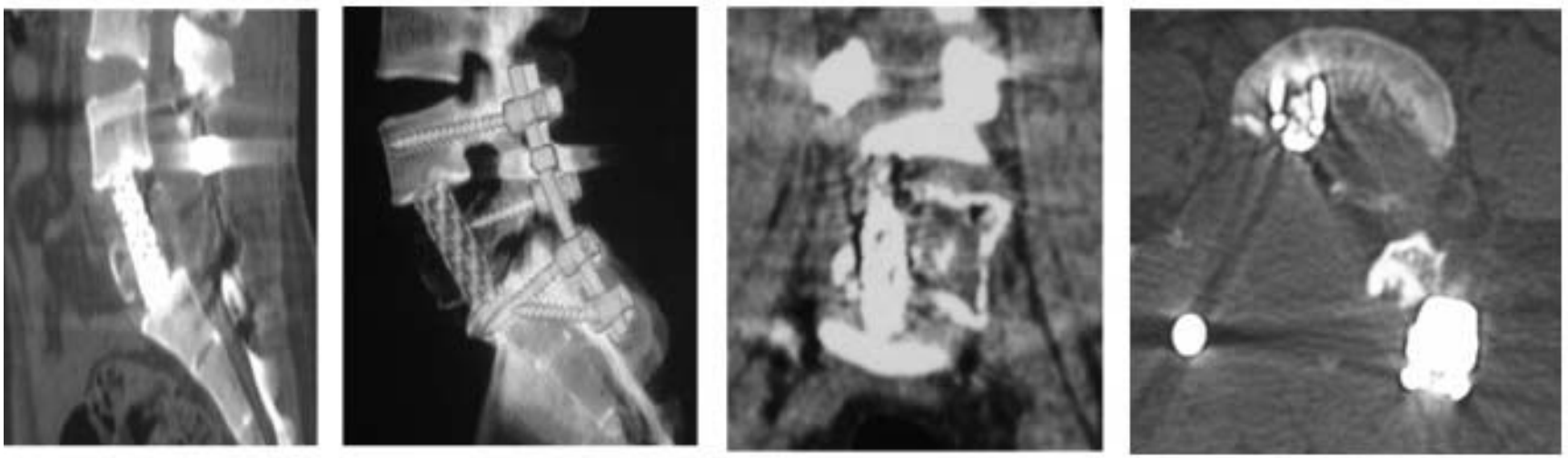

\section{CT Scan at 2 years Interval with Minimal Sclerosis}

Figure 3. Postoperative radiographs and computed tomography (CT) scans of giant cell tumor of bone L5 vertebrae.

the lowest if high-speed burring of the margins after curettage and bone cement packing is used. ${ }^{22-26}$

Treatment for "typical" appendicular GCT is well established, but recommendations on treating tumors of rare localizations, such as small bones, pelvis, spine, or sacrum, are still unclear. ${ }^{27,28}$ Tumors of the axial skeleton, especially spine and sacrum, seem to be particularly complicated to treat. This is mainly due to limited surgical accessibility and proximity to spinal cord and nerve roots. Possible treatments range from intralesional resection to en bloc spondylectomy with various adjuncts, such as irradiation or arterial emboliza- tion. $^{29-34}$ After reports of the effectiveness of the bisphosphonates in the peripheral GCTB, ${ }^{35}$ we started our patients on the postoperative bisphosphonates.

In diseases like skeletal metastasis, Paget disease, osteoporosis, and multiple myeloma, ${ }^{24,36}$ the effectiveness of bisphosphonates has already been established in preventing osteolysis associated with them. Osteolysis occurring as a result of fibrous dysplasia and Langherans cell histiocytosis can also be treated with the help of bisphosphonates. ${ }^{36-38}$ The effectiveness of bisphosphonates in GCTB have been depicted by following 2 studies. In the study by

Table 2. Patients who did not receive bisphosphonates in the postoperative period.

\begin{tabular}{|c|c|c|c|c|c|c|}
\hline Name & Age, y/Sex & Site & Sclerosis $+/-$ & Neurology Preoperative & Neurology Postoperative & Recurrence \\
\hline JM & $55 / \mathrm{M}$ & GCT L5 & Absent but fusion + & Asia C & Asia C & Present after $20 \mathrm{mo}$ \\
\hline $\mathrm{Y}$ & $34 / \mathrm{M}$ & GCT right sacrum & Absent but fusion + & Asia E & Asia E & Absent \\
\hline $\mathrm{Sh}$ & $17 / \mathrm{M}$ & GCT L4 & Absent but fusion + & Asia E & Asia E & Absent \\
\hline $\mathrm{Gp}$ & $39 / \mathrm{F}$ & GCT sacrum & Absent but fusion + & Asia E & Asia E & Present after $1 \mathrm{y}$ \\
\hline $\mathrm{KA}$ & $16 / \mathrm{F}$ & GCT L5 vertebrae & Absent but fusion + & Asia E & Asia E & Absent \\
\hline S & $28 / \mathrm{F}$ & GCT sacrum & Absent but fusion + & Asia E & Asia E & Absent \\
\hline
\end{tabular}

Abbreviation: GCT, giant cell tumor. 
Table 3. Comparison of two groups.

\begin{tabular}{lll}
\hline & \multicolumn{1}{c}{ Group 1 } & Group 2 \\
\hline Age, y (minimum-maximum) & $24(13-33)$ & $36(17-55)$ \\
Sex ratio, M:F & $1: 5$ & $4: 3$ \\
Distribution & 2 dorsal, 1 lumbar, and 3 sacrum & 4 lumbar and 3 sacrum \\
Excision only, $\mathrm{n}$ & 2 & 3 \\
Excision + reconstruction, $\mathrm{n}$ & 4 & 4 \\
Recurrence, $\mathrm{n}$ & 0 & 2 \\
Sclerosis & Present in all 6 patients & Absent in all 7 patients \\
VAS & Preoperative 6 & Preoperative 7 \\
& Postoperative 2 & Postoperative 4 \\
ODI & Preoperative 65 & Preoperative 63 \\
& Postoperative 8 & Postoperative 15 \\
\hline
\end{tabular}

Abbreviations: ODI, Oswestry Disability Index; VAS, visual analog scale.

Tse et $\mathrm{al}^{39} 1$ of 24 patients $(4.2 \%)$ in the bisphosphonate group developed local recurrence, whereas the control group, which received no bisphosphonates, had a recurrence rate of $30 \%$. Use of intravenous bisphosphonate has also been reported in 1 case report to control the growth of a giant cell tumor of the sacrum. ${ }^{40}$ Bisphosphonates inhibit osteoclast-mediated bone resorption by mimicking pyrophosphates. There occurs a change in the physicochemical structure of the hydroxyapatite crystal when bisphosphonates bind to hydroxyapatite. $^{23,24}$ Farnesyl diphosphate synthase, an enzyme in the mevalonate pathway is inhibited by amino bisphosphonates, which further inhibits the formation of osteoclasts from mononuclear phagocyte precursors. This results in decreased osteoclast resorption due to effects on the cytoskeleton, vesicular trafficking, and membrane ruffling, and increased osteoclast apoptosis. ${ }^{32-34}$ Studies have shown that bisphosphonates induce apoptosis of stromal cells and osteoclasts in giant cell tumor of bone. $^{36,41,42}$ GCTB contains numerous mature, functional osteoclasts which induce extensive osteolysis in the growing phase. Bisphosphonates mediate a decrease in the number of osteoclasts, resulting in decreased resorption carried out by osteoclasts in these tumors. This mechanism of action may be particularly helpful in cases of spine GCTBs because of all the difficulties mentioned earlier in their treatment.

Bisphosphonates are considered to be quite safe, and maximum safe duration to use the bisphosphonates is considered to be up to 5 years. ${ }^{43}$ But in most of the studies pertaining to their role as an adjuvant in GCTB, they were used for 2 to 3 years. ${ }^{8}$ Protocols of drug administration vary depending upon the type of bisphosphonate used. Zhang et $\mathrm{al}^{35}$ reported that sodium ibandronate was also equally effective in treating the recurrent giant cell tumor of the spine in 3 cases. Oral alendronate can be given in $70 \mathrm{mg} /$ wk or $10 \mathrm{mg}$ daily dose. We gave alendronate in a 10 mg daily dose for a period of 2 years to all the patients who underwent operation after 2008 at our institute. In all patients, treatment was correlated with the regular radiologic follow-up. In all the patients we were able to achieve successful disease remission, and this correlated well with sclerosis on the radiologic assessment. All the patients complied well with treatment regimen in postoperative management. There may be increased concern of recurrence, in case of any default while on treatment. However, to the best of our knowledge, it is not mentioned in the literature.

A recurrence rate of $50 \%$ has been reported in GCTB of the vertebra above sacrum by Dahlin et al. ${ }^{44}$ But other studies report a rate of recurrence around 25\% in GCT spine. This implies that GCTB of spine has high rates of recurrence even after adequate treatment. But this generalization cannot be placed on firm footing, because literature provides only small case series of the spine or sacral GCTB with short follow-up periods. ${ }^{29,30,32,33,37,40}$ Our study had an average follow-up of 37.88 months, with a minimum follow-up of 18 months. In our study, 2 of 13 patients $(15.4 \%)$ had a recurrence. Both of these patients were from the group that did not receive bisphosphonates postoperatively. This connotes that postoperative bisphosphonates may be helpful in preventing recurrence in spine GCTB, but this was not confirmed statistically because the sample size of the study was small. In postoperative CT scans of all of the patients who received bisphosphonates, increased mineralization, increased cortical thickness of the remaining bone, new bone formation, and increased trabecular density were present.

Recently, there has been interest in a new method of application of bisphosphonates. Zwolak et al, ${ }^{45}$ 
Kazutaka et al, ${ }^{46}$ and Nishisho et $\mathrm{al}^{47}$ have reported the effectiveness of zoledronic acid-loaded hydroxyapatite and bone cement in giant cell tumor and other malignant tumors, such as multiple myeloma and renal cell carcinoma.

Moreover, there is now considerable evidence that in cases of poor surgical candidates and in patients with unresectable or metastatic tumors bisphosphonates can be used as stand-alone therapy. ${ }^{9,48,49}$ But still, high-speed burring of the margins after curettage and bone cement packing is considered to be the best treatment by most of the surgeons for the appendicular GCTB. ${ }^{22-26}$ However, recently denosumab, a RANKL inhibitor, has been approved by the US Food and Drug Administration for adults and skeletally mature adolescents with unresectable GCTB or when surgical resection is likely to result in severe morbidity. ${ }^{50}$

Sclerosis in postoperative CT scans of all the patients who received bisphosphonates along with no recurrence of tumor in the bisphosphonate group signifies that bisphosphonates in the postoperative period have a positive effect on the final disease outcome. It also implies that bisphosphonates are good and safe adjuvants that can be used effectively with appropriate surgical modality.

A major limitation of this study is the small number of patients. Because spine GCTs are quite rare, the sample size has been a major problem in all the studies in the literature. But the follow-up period in our study is quite long. Moreover, the protocol for the dosage of the bisphosphonates has also not yet been standardized. We administered the $10 \mathrm{mg}$ daily dose of alendronate, and it seemed to be fairly effective because postoperative sclerosis was visible in all the patients.

\section{CONCLUSION}

The complex anatomy of the spine and the difficulty of surgical resection require a better treatment modality that is easy to use, safe, effective, and nontoxic. From our study it can be inferred that spinal GCTBs are slightly more common in females; are most common in the second and third decades of life; and that bisphosphonates are easy to administer, effective, and safe adjuvant therapy, along with appropriate surgical intervention in spinal GCTBs, and they may have a role in decreasing the recurrence of the tumor, although studies with larger sample sizes are required to put this hypothesis on firm footing.

\section{REFERENCES}

1. Sung HW, Kuo DP, Shu WP, Chai YB, Liu CC, Li SM. Giant-cell tumor of bone: analysis of two hundred and eight cases in Chinese patients. J Bone Joint Surg Am. 1982;64(5):755-761.

2. Settakorn J, Lekawanvijit S, Arpornchayanon O, et al. Spectrum of bone tumors in Chiang Mai University Hospital, Thailand according to WHO classification 2002: a study of 1,001 cases. J Med Assoc Thai. 2006;89(6):780-787.

3. Xing R, Yang J, Kong Q, Tu C, Zhou Y, Duan H. Giant cell tumour of bone in the appendicular skeleton: an analysis of 276 cases. Acta Orthop Belg. 2013;79(6):731-737.

4. Thangaraj R, Grimer RJ, Carter SR, Stirling AJ, Spilsbury J, Spooner D. Giant cell tumour of the sacrum: a suggested algorithm for treatment. Eur Spine J. 2010;19(7):1189-1194.

5. Murphey MD, Andrews CL, Flemming DJ, Temple HT, Smith WS, Smirniotopoulos JG. From the archives of the AFIP: primary tumors of the spine: radiologic pathologic correlation. Radiographics. 1996;16(5):1131-1158.

6. Maurice B, Henrichs MP, Gosheger G, et al. Giant cell tumors of the axial skeleton. Sarcoma. 2012;2012:410973.

7. Bhojraj SY, Nene A, Mohite S, Varma R. Giant cell tumor of the spine: a review of 9 surgical interventions in 6 cases. Indian J Orthop. 2007;41(2):146-150.

8. Kaiser PB, Compton JT, Caldwell JME, Hickernell TR, Lee FY. Systemic therapy in patients with resectable and unresectable cases of giant cell tumor: a systematic review. $J$ Cancer Ther. 2014;5:339-353.

9. Balke M, Campanacci L, Gebert C, et al. Bisphosphonate treatment of aggressive primary, recurrent and metastatic giant cell tumour of bone. BMC Cancer. 2010;10:462.

10. Cooper A, Travers B. Surgical Essays. 3rd ed. London, England: Cox \& Son; 1818.

11. Jaffe HL, Lichtenstein L, Portis RB. Giant cell tumor of bone: its pathologic appearance, grading, supposed variants and treatment. Arch Pathol. 1940;30:993-1031.

12. Manaster BJ, Doyle AJ. Giant cell tumors of bone. Radiol Clin North Am. 1993;31(2):299-323.

13. Mirra JM. Bone Tumors: Clinical, Radiologic, and Pathologic Correlations. Philadelphia, PA: Lea \& Febiger; 1989.

14. Hunter CL, Pacione D, Hornyak M, Murali R. Giantcell tumors of the cervical spine: case report. Neurosurgery. 2006;59(5):E1142-E1143; discussion E1143.

15. Sanjay BK, Sim FH, Unni KK, McLeod RA, Klassen RA. Giant-cell tumours of the spine. J Bone Joint Surg Br. 1993;75(1):148-154.

16. Unni KK. Dahlin's Bone Tumors: General Aspects and Data on 11,087 Cases. Philadelphia, PA: Lippincott-Raven; 1996.

17. Hart RA, Boriani S, Biagini R, Currier B, Weinstein JN. A system for surgical staging and management of spine tumors: a clinical outcome study of giant cell tumors of the spine. Spine (Phila Pa 1976). 1997;22(15):1773-1783.

18. Carrasco CH, Murray JA. Giant cell tumors. Orthop Clin North Am. 1989;20(3):395-405.

19. Salzer-Kuntschik M. Differential diagnosis of giant cell tumor of bone [in German]. Verh Dtsch Ges Pathol. 1998;82:154-159. 
20. Campanacci M. Bone and Soft Tissue Tumors. New York, NY: Springer; 1990.

21. Larsson SE, Lorentzon R, Boquist L. Giant cell tumor of bone: a demographic, clinical, and histopathological study of all cases recorded in the Swedish cancer registry for the years 1958 through 1968. J Bone Joint Surg Am. 1975;57(2):167-173.

22. Campanacci M, Baldini N, Boriani S, Sudanese A. Giant-cell tumor of bone. $J$ Bone Joint Surg Am. 1987;69(1):106-114.

23. Blackley HR, Wunder JS, Davis AM, White LM, Kandel $\mathrm{R}$, Bell RS. Treatment of giant-cell tumors of long bones with curettage and bone-grafting. J Bone Joint Surg Am. 1999;81(6):811-820.

24. Goldenberg RR, Campbell CJ, Bonfiglio M. Giant cell tumor of bone: an analysis of two hundred and eighteen cases. $J$ Bone Joint Surg Am. 1970;52(4):619-664.

25. Lausten GS, Jensen PK, Schiodt T, Lund B. Local recurrences in giant cell tumour of bone: long-term follow up of 31 cases. Int Orthop. 1996;20(3):172-176.

26. Malek F, Krueger P, Hatmi ZN, Malayeri AA, Faezipour H, O'Donnell RJ. Local control of long bone giant cell tumour using curettage, burring and bone grafting without adjuvant therapy. Int Orthop. 2006;30(6):495-498.

27. Balke M, Schremper L, Gebert C, et al. Giant cell tumor of bone: treatment and outcome of 214 cases. Res Clin Oncol. 2008;134(9):969-978.

28. Freyschmidt J, Ostertag H, Jundt G. Knochentumoren. 2. 3rd edition. Auflage, Berlin, Germany: Springer; 1998.

29. Martin C, McCarthy EF. Giant cell tumor of the sacrum and spine: series of 23 cases and a review of the literature. Iowa Orthop J. 2010;30:69-75.

30. Turcotte RE, Biagini R, Sim FH, Unni KK. Giant cell tumor of the spine and sacrum. Chir Organi Mov. 1990;75(1):104-107.

31. Blackley HR, Wunder JS, Davis AM, White LM, Kandel $\mathrm{R}$, Bell RS. Treatment of giant-cell tumors of long bones with curettage and bone-grafting. $J$ Bone Joint Surg Am. 1999;81(6):811-820.

32. Guo W, Ji T, Tang X, Yang Y. Outcome of conservative surgery for giant cell tumor of the sacrum. Spine (Phila $\mathrm{Pa}$ 1976). 2009;34(10):1025-1031.

33. Fidler MW. Surgical treatment of giant cell tumours of the thoracic and lumbar spine: report of nine patients. Eur Spine J. 2001;10(1):69-77.

34. Donthineni R, Boriani L, Ofluoglu O, Bandiera S. Metastatic behaviour of giant cell tumour of the spine. Int Orthop. 2009;33(2):497-501.

35. Zhang W, Zhang Y, Li P, Rhodesm SD, Wang Y, Xue $\mathrm{X}$. Administration of sodium ibandronate in the treatment of complicated giant cell tumor of the spine. Spine. 2011;36(17):E1166-E1172.

36. Sanjay BKS, Sim FH, Unni KK, McLeod RA, Klassen RA. Giant-cell tumours of the spine. J Bone Joint Surg $\mathrm{Br}$. 1993;75(1):148-154.

37. Leggon RE, Zlotecki R, Reith J, Scarborough MT. Giant cell tumor of the pelvis and sacrum: 17 cases and analysis of the literature. Clin Orthop Relat Res. 2004;423:196-207.

38. Osaka S, Toriyama S. Surgical treatment of giant cell tumors of the pelvis. Clin Orthop Relat Res. 1987;222:123-131.

39. Shikata J, Yamamuro T, Shimizu K, Shimizu K,
Kotoura Y. Surgical treatment of giant-cell tumors of the spine. Clin Orthop Relat Res. 1992;278:29-36.

40. Savini R, Gherlinzoni F, Morandi M. Surgial treatment of giant-cell tumor of the spine: the experience at the Istituto Ortopedico Rizzoli. J Bone Joint Surg Am. 1983;65(9):12831289.

41. Donthineni R, Boriani L, Ofluoglu O, Bandiera S. Metastatic behaviour of giant cell tumour of the spine. Int Orthop. 2009;33(2):497-501.

42. Enneking WF. Staging of musculoskeletal tumors. In: Enneking WF, ed. Musculoskeletal Tumor Surgery. Vol. 1. New York, NY: Churchill Livingstone; 1983:87-88.

43. Black DM, Bauer DC, Schwartz AV, Cummings SR, Rosen CJ. Continuing bisphosphonate treatment for osteoporosis-for whom and for how long? $N$ Engl $J$ Med. 2012;366:2051-2053.

44. Dahlin DC. Giant-cell tumor of vertebrae above the sacrum: a review of 31 cases. Cancer. 1977;39(3):1350-1356.

45. Zwolak P, Manivel JC, Jasinski P, et al. Cytotoxic effect of zoledronic acid-loaded bone cement on giant cell tumor, multiple myeloma, and renal cell carcinoma cell lines. $J$ Bone Joint Surg Am. 2010;92(1):162-168.

46. Koto K, Murata H, Sawai Y, Ashihara E, Horii M, Kubo T. Cytotoxic effects of zoledronic acid-loaded hydroxyapatite and bone cement in malignant tumors. Oncol Lett. 2017;14(2):1648-1656

47. Nishisho T, Hanaoka N, Endo K, Takahashi M, Yasui N. Locally administered zoledronic acid therapy for giant cell tumor of bone. Orthopedics. 2011;34(7):e312-e315.

48. Gille O, Oliveira Bde A, Guerin P, Lepreux S, Richez C, Vital JM. Regression of giant cell tumor of the cervical spine with bisphosphonate as single therapy. Spine (Phila Pa 1976). 2012;37(6):E396-E399.

49. Cornelis F, Truchetet ME, Amoretti N, et al. Bisphosphonate therapy for unresectable symptomatic benign bone tumors: a long-term prospective study of tolerance and efficacy. Bone. 2014;58:11-16.

50. Palmerini E, Chawla NS, Ferrari S, et al. Denosumab in advanced/unresectable giant-cell tumour of bone (GCTB): for how long? Eur J Cancer. 2017;76:118-124.

Disclosures and COI: The authors received no funding for this study and report no conflicts of interest.

Corresponding Author: Chaitanya Dev Pannu, Department of Orthopaedics, All India Institute of Medical Sciences (AIIMS), New Delhi, India, 110023. Phone: +91996 8037279; Email: cdpannu@ gmail.com.

Published 21 December 2018

This manuscript is generously published free of charge by ISASS, the International Society for the Advancement of Spine Surgery. Copyright (C) 2018 ISASS. To see more or order reprints or permissions, see http://ijssurgery.com. 